\title{
El movimiento indígena como víctima del conflicto armado en Colombia y su apuesta por una paz desde una visión territorial
}

\author{
CARLOS ALBERTO OSORIO CALVO* \\ MELANIA SATIZABAL REYES**
}

Recibido: 7 de junio de 2018 - Evaluado: 17 de noviembre de 2019 - Aceptado: 12 de diciembre de 2019

Citar como: Osorio Calvo, C. A. y Satizabal Reyes, M. (2020). El movimiento indígena como víctima del conflicto armado en Colombia y su apuesta por una paz desde una visión territorial. Hallazgos, 17(33), 197-219. DoI: https://doi.org/10.15332/2422409X.4369

* Doctorando en Educación. Docente de la Universidad del Valle, Colombia. Correo electrónico: carlos.alberto.osorio@correounivalle.edu.co ORCID: https://orcid.org/0000-0002-4807-9171

** Magíster en Sociología. Docente de la Universidad del Valle, Colombia. Correo electrónico: melania.satizabal@correounivalle.edu.co ORCID: https://orcid.org/0000-0003-0793-6031 


\section{Resumen}

En este artículo se presenta una reflexión basada en el testimonio de indígenas colombianos pertenecientes a la Organización Nacional Indígena de Colombia (ONIC), sobre la forma en que algunas comunidades y varios capítulos del movimiento indígena colombiano perciben la afectación que ha tenido el conflicto armado en la vida de los pueblos. Se ofrece una reflexión sobre la paz en el contexto de las tensiones que crea el hecho de poner en marcha un acuerdo con una de las insurgencias armadas en Colombia. Este texto presenta la apuesta por una comprensión de la paz dentro de las cosmovisiones de los pueblos indígenas y en particular de la relación configurada con el territorio. Los materiales testimoniales y documentales se derivan de un amplio trabajo de investigación realizado en el periodo 2012-2016 sobre la manera en que el conflicto armado ha afectado la autonomía del movimiento indígena en Colombia.

Palabras clave: conflicto, movimiento indígena, movimientos sociales, paz, territorio, víctimas. 


\title{
The indigenous movement as victim of the armed conflict in Colombia and its commitment to peace from a territorial vision
}

\begin{abstract}
This article presents a reflection based on the testimony of Colombian indigenous people belonging to the National Indigenous Organization of Colombia (ONIC), on how some communities and several chapters of the Colombian indigenous movement perceive the impact that the armed conflict has had on the life of the people. A reflection is offered on peace in the context of the tensions created by setting into motion an agreement with one of the armed insurgencies in Colombia. This paper presents the commitment to an understanding of peace within the worldviews of indigenous peoples and in particular of the relationship formed with the territory. The testimonial and documentary materials are derived from extensive research work carried out in the 2012-2016 period on how the armed conflict has affected the autonomy of the indigenous movement in Colombia.
\end{abstract}

Keywords: conflict, indigenous movement, social movements, peace, territory, victims.

\section{O movimento indígena como vítima do conflito armado na Colômbia e sua opção por uma paz desde uma visão territorial}

\section{Resumo}

Neste artigo apresenta-se uma reflexão baseada na testemunha de indígenas colombianos pertencentes à Organização Nacional Indígena da Colômbia (ONIC), sobre a forma na qual algumas comunidades e vários setores do movimento indígena colombiano percebem a afetação que tem tido o conflito armado na vida dos povos. Oferece-se uma reflexão sobre a paz no contexto das tensões que cria o fato de implementar um acordo com uma das insurgências armadas na Colômbia. Este texto apresenta a opção por uma compreensão da paz dentro das cosmovisões dos povos indígenas e em particular da relação configurada com o território. Os materiais testemunhais e documentais derivam-se de um amplo trabalho de pesquisa realizado no período 2012-2016 sobre a maneira na qual o conflito armado tem afetado a autonomia do movimento indígena na Colômbia.

Palavras-chave: conflito, movimento indígena, movimentos sociais, paz, território, vítimas. 


\section{Introducción}

Una reflexión acerca de la manera como se analiza, según la teoría, la relación entre el movimiento indígena colombiano, en cuanto movimiento social, y el conflicto armado nos lleva a presentar en este artículo el movimiento indígena como un actor social que desde su cosmovisión expone un horizonte epistemológico para referirse a su visión de una paz que pasa por considerar las relaciones con el territorio. Esta indagación se ubica en el contexto marcado tras la firma del acuerdo final para la terminación del conflicto armado entre el Estado colombiano y la guerrilla de las FARC. La pregunta que orienta el estudio es: ¿cómo el conflicto armado en Colombia, al desarrollarse en los territorios ancestrales de los pueblos originarios, genera victimización de las comunidades indígenas, y en qué sentido una visión de la paz, desde las cosmovisiones de estos pueblos, pasa necesariamente por la armonización de las relaciones en el territorio y con el territorio?

El estudio combina el análisis documental y etnográfico a partir del desarrollo de las categorías movimiento indígena, victimización colectiva y territorio. Las categorías se construyen en el escenario del conflicto armado colombiano según la discusión teórica de los casos empíricos derivados de fuentes testimoniales de activistas pertenecientes al movimiento indígena. La noción de movimiento social parte de la perspectiva de Alain Touraine, que la entiende como los actores colectivos que disputan, desde sus identidades culturales, el sentido de lo social. A la par con esta matriz teórica, el movimiento indígena colombiano es visto desde el enfoque de las sociedades en movimiento de Raúl Zibechi, quien caracteriza el accionar de los pueblos en América Latina desde la lucha a partir de valores ancestrales. La relación entre pueblos indígenas y territorio y la consecuente visión del conflicto en perspectiva de colonialidad se analizan con base en las propuestas de algunos investigadores del proyecto modernidad-colonialidad, como Catherine Walsh, Arturo Escobar y Walter Mignolo.

Tras la lectura de los testimonios de actores indígenas, con los aportes de los autores mencionados se construye, como principal conclusión de este trabajo de reflexión, una interpretación de los conceptos de conflicto, paz y reconciliación. Tal interpretación atiende las cosmovisiones de los pueblos originarios, y a partir de tal lectura se enuncia una postura epistémica que asume que el principal aporte de los pueblos originarios a la construcción de paz es su forma armónica de relacionarse con el territorio. Debido a que el territorio ha sido herido y desarmonizado por las acciones de conflicto, y en la medida en que los pueblos indígenas han sido víctimas 
de la guerra, la reconciliación pasa necesariamente por el restablecimiento de relaciones armónicas en el territorio y con el territorio, de acuerdo con las cosmovisiones de los pueblos.

\section{El movimiento indígena como víctima del conflicto armado en Colombia}

En 2016 se firmó el acuerdo para la terminación del conflicto armado entre el Gobierno colombiano y la guerrilla de las FARC-EP. Como consecuencia de este acuerdo, se desató en el país un amplio debate que se extiende hasta el presente y que impacta diversos sectores de la vida social y política. Desde el comienzo de la negociación, y en lo que va de la implementación de los acuerdos, se han excluido las voces de los grupos étnicos. Solo hacia el final del proceso de conversaciones, luego de hacer incidencia política a través de la movilización, se logró incluir el capítulo étnico en el Acuerdo Final para la Terminación del Conflicto y la Construcción de una Paz Estable y Duradera. Este capítulo pone de manifiesto la necesidad de asegurar que se tengan en cuenta las cosmovisiones en la construcción de la paz. Atendiendo a estas cosmovisiones, la paz comporta el restablecimiento de la armonía, la reparación de la identidad cultural, los daños al territorio y al tejido social. Con base en esta visión es imperativo respetar la autonomía territorial y las formas de vida en el territorio (Rodríguez, 2018). De acuerdo con esta consideración de la relación ancestral con el territorio se analizará en este artículo la comprensión de paz que configuran los pueblos originarios, como aporte a la superación del conflicto social y armado que vive el país.

Dentro de la comprensión y las cosmovisiones desarrolladas por los pueblos originarios de lo que hoy es América Latina, el territorio guarda una relación especial con la comunidad y la vida tanto individual como colectiva. El territorio es la casa común de los pueblos. Comporta la posesión colectiva de tierras y el uso de estas desde las tradiciones ancestrales. Supone, entonces, el ejercicio de la autoridad de los pueblos sobre estas. El conflicto armado en Colombia ha lesionado la vida, la comunidad, el territorio y la posibilidad de paz para los pueblos originarios, y por eso debe pasar por la reconciliación en el territorio y con el territorio.

La confrontación vivida en Colombia ha dejado víctimas, y en esa medida la construcción de paz demanda reconciliación. Existen diferentes formas de concebir el perdón. En términos jurídicos, “el perdón se da cuando hay una acción del Estado que permite disminuir o eliminar la pena que corresponde al delito que cometió una 
persona. En contextos de violencia política se da cuando se ha negociado, o se han desmovilizado los grupos armados” (Villa, 2016, p. 10). En términos psicosociales, implica que los sujetos se confronten con sus experiencias e historias. Es un proceso en el cual

[...] el sujeto se confronta delante de sí mismo y de su entorno, frente a su concepción espiritual, frente a su vivencia, emociones, procesos propios, su lectura del contexto y de los hechos, y asume una posición en un movimiento que le devuelve su propio poder y dignidad, incluso frente al ofensor. (Villa, 2016, p. 11)

El perdón, en el marco de una construcción antropocéntrica, puede ser entendido como un sentimiento que implica reconocer la humanidad del agresor. Es un proceso de fortaleza subjetiva y de dignidad del ofendido. Posibilita la superación del odio y del deseo de venganza, y desde ese lugar contribuye a la reivindicación de los derechos, la movilización y la transformación de las injusticias sociales (Villa, 2016). Los pueblos originarios han desarrollado una visión ecocéntrica de la vida que impacta sus mismas comprensiones de categorías como conflicto, paz, reconciliación y perdón.

Colombia está frente al desafío de consolidar una paz estable y duradera que ha de pasar por la finalización del conflicto armado. En lo avanzado de la implementación del acuerdo de paz con la guerrilla de las FARC es evidente una creciente polarización de la opinión ciudadana en torno a este, y un preocupante incremento de las cifras de muertes violentas ligadas al conflicto armado, incluidas las de excombatientes. El país asiste a una oleada de violencia en contra de los líderes sociales y, de manera particular, en contra de los miembros de las comunidades ancestrales en territorios de resguardos. Muchos de estos actos permanecen aún en la impunidad. El reconocimiento de las víctimas y de las acciones cometidas por los victimarios resulta clave para avanzar en la superación de la impunidad y en la reconciliación como camino hacia una paz estable y duradera. En anteriores procesos de negociación con grupos armados en Colombia quedó un alto nivel de impunidad, lo que ha contribuido a que la reconciliación no sea efectiva.

En la consideración en torno al perdón, la reconciliación, la justicia y la paz hay que atender también a un enfoque diferencial respecto a los pueblos originarios. La construcción de la paz requiere de nuevas comprensiones de la reconciliación y la justicia. Para el caso de los pueblos originarios, su visión de la justicia está ligada a sus cosmovisiones y sus relaciones en el territorio y con el territorio. En tal sentido, está más caracterizada por una lógica del nosotros, de la comunalidad (Meza, 2016). Escobar (2003) construye la idea de comunalidad de acuerdo con la manera en que 
se dan las relaciones entre las comunidades ancestrales, y en consecuencia con tales relaciones se demanda la generación de políticas desde estas y hacia estas. Esto significa para él la superación de visiones dualistas y estadocéntricas de organización social y manejo del territorio.

Los indígenas han sido y son protagonistas de primer orden en el conflicto armado. Han sido y continúan siendo víctimas por cuenta del desplazamiento forzado, la presencia de combates en sus territorios, el reclutamiento, la imposición de economías legales e ilegales basadas en el monocultivo y la extracción de minerales, entre otros. Ser indígenas, con sus cosmovisiones, usos, tradiciones y costumbres, ha sido una realidad negada por las élites del poder y por los elementos armados ligados a estas. El conflicto toca el corazón mismo de su ser en cuanto grupos étnicos. En la construcción de sus acciones como movimiento social han ido también construyendo una lectura del conflicto y de la paz. Han logrado ofrecer al país una mirada de la paz que considera la manera en que desde su cosmovisión entienden tanto la guerra como la paz.

\section{Movimiento indígena como movimiento social}

La mirada que para este trabajo se ha escogido de los movimientos sociales los ubica como actores más determinados en su identidad por elementos de orden cultural, cuyas acciones interpretan la defensa de valores que forman parte de su carácter diferencial, que se pueden instituir en valores para el conjunto de la sociedad. En este sentido, se asume el planteamiento de Touraine (2010), quien considera que en el mundo contemporáneo los sujetos se configuran como tales por cuanto son portadores de derechos que pueden ser reconocidos por otros actores. En esta interpretación se puede inscribir el movimiento indígena colombiano, en cuanto actor que se transforma en sujeto en la medida en que se reconoce violentado en sus derechos, por cuenta de un conflicto social y su expresión armada. Además es poseedor de unas características diferenciales de identidad que han de ser reconocidas, respetadas e incluidas en la construcción de una paz, fruto de la justicia, para ellos y para el grueso de los colombianos.

El movimiento indígena en Colombia se entiende en el marco de la existencia de un conflicto. Los movimientos sociales se caracterizan por ser expresiones del sujeto y su conflicto con el mercado y la mercantilización de la vida; más concretamente contra la pérdida de la identidad, contra el autoritarismo de las lógicas de poder que se despliegan en el mundo. Se reconoce su presencia cuando aparece una lucha por el sujeto y sus derechos en el marco de un conflicto en el que este sujeto se disputa la 
gestión de los medios de acción. Su lucha es por el rescate de la identidad del sujeto. Este conflicto pone al sujeto a cuestionar las formas de dominación y el modo de conducción de la vida misma desde la forma de utilización de los recursos y modelos culturales. Es así que luchan por la construcción de la democracia desde la afirmación del sujeto y sus derechos (Touraine, 1998).

Touraine (1999) plantea que desde la década de los ochenta los movimientos con mayor impacto son los que defienden derechos ligados a la cultura. Estos movimientos dirigen su lucha en nombre de valores que se pretenden esenciales para el conjunto de la sociedad. La reivindicación de estos movimientos está ligada a la defensa de los derechos culturales y sociales de individuos y de minorías que son ubicadas al margen por las relaciones económicas imperantes en el mundo. Al ser puestas al margen, su condición de sujetos y de actores se activa en tanto luchan por la defensa del derecho de todos a una existencia libre y humana, por el derecho a la igualdad cultural, por la necesidad de defender los derechos en contextos en los que se desconoce la diversidad de los sujetos en la tentativa de homogeneización propia del mercado globalizado.

Para Touraine, la conflictividad social es un detonante de los movimientos sociales y los conflictos en los que se disputa el sentido de lo social, desde disputas de orden cultural como protagonistas de la movilización. Para el caso de América Latina, y en particular para el análisis del movimiento indígena en Colombia, conviene ofrecer una perspectiva que permita dar cuenta de elementos más ligados a sus cosmovisiones. En tal sentido, Escobar (2018) plantea que más que movimientos sociales, los pueblos originarios pertenecen a verdaderos mundos en movimiento. Esta idea conecta con la comprensión de Zibechi (2015) de sociedades en movimiento.

Esta idea de movimiento social alude entonces al carácter conflictivo de la acción, a la disputa por el sentido de lo social y a la puesta en escena de cosmovisiones que desafían las lógicas monoculturales de producción de comprensiones y relaciones. Ya desde Touraine se decía que un escenario de la disputa de los movimientos sociales es el mercado y la mercantilización de la vida. Escobar (2018) se refiere a este escenario de disputa como la episteme moderna y enfrenta al discurso del desarrollo el discurso enarbolado a partir del enunciado nasa de liberación de la Madre Tierra, derivado de la cosmovisión de este pueblo.

La matriz desarrollista moderna impone unas reglas de discurso y posibilita unas limitadas y determinadas prácticas en el marco del capitalismo. Pretender que los pueblos originarios deben actuar según el discurso del desarrollo, que no les 
es propio y que no se corresponde con sus prácticas de vida y sus pensamientos, es imponer la eliminación de sus particularidades. Es esta una expresión del conflicto central, en la cual los pueblos originarios de Colombia se convierten en víctimas y se disputan el sentido de lo social. El conflicto armado en Colombia tiene como elemento central la disputa territorial. La comprensión ancestral de territorio se opone a la lógica económica que el capitalismo, el conflicto armado y los actores de poder imponen sobre las zonas habitadas por comunidades ancestrales.

La modernidad, dice Escobar (2011), centrada en el individuo, lo concibe sin pertenencia a la naturaleza, sin lugar, sin comunidad, sin territorio. Para Walsh (2009), la modernidad se da en el pensamiento europeo desde la lógica de la colonialidad. En tal sentido, modernidad y colonialidad van de la mano. Para el caso de América Latina, se habla de colonialidad del poder, del ser y del saber. La colonialidad es un campo en el que se disputan prácticas discursivas y saberes. Disputa que hasta ahora ha sido bastante desigual, puesto que la modernidad-colonialidad ha provocado la destrucción de saberes otros y relaciones diversas y la imposición por fuerza de las armas de formas de uso y explotación de la tierra.

Para imponer la idea de un único y verdadero modelo de razón, de ciencia, de civilización, de desarrollo, de discurso, la episteme moderna requiere producir el discurso de racialización. La episteme moderna desde el poder y su colonialidad establece un sistema social de clasificación y exclusión basado en la categoría de raza (Walsh, 2009). El conflicto social que causa la victimización de los pueblos originarios es, para el caso de Colombia, también un conflicto racial. El discurso económico del desarrollo como proyecto crea la otredad con base en la inferiorización (Escobar, 2011). Desde esta construcción discursiva, se privilegian sectores de la economía basados en la explotación minero-energética en el territorio de las comunidades ancestrales, pasando por encima de las comprensiones, usos y costumbres de los pueblos. Zibechi (2015) insiste en que una economía extractivista, además de producir irreparables daños a la naturaleza, mantiene la lógica de sumisión de los pueblos y sus economías.

El daño a la naturaleza provoca conflicto con las comunidades y su victimización. Este es el efecto de la relación mercantil que se establece con ella según este paradigma del desarrollo. Tal relación supone una confrontación entre la cosmovisión indígena y la episteme moderna. La modernidad es antropocéntrica (Escobar, 2018). El individuo racional no tiene comunidad y está radicalmente separado de la naturaleza (Escobar, 2003). Está separado porque la modernidad impone una lógica binaria, dicotómica, desde la cual se implantan prácticas de exclusión y 
subalternización. A partir de la división colonial entre Occidente y no-Occidente se opera la oposición cultura-naturaleza (Escobar, 2018).

La razón de ser de esta ontología de la separación, según Escobar (2018), es la dominación a partir de la construcción discursiva de la inferioridad del otro. Se produce así la colonialidad del poder y del saber que impacta en los pueblos otros. Desde la invasión y colonización de lo que hoy es América Latina se impone no solo el sistema mundo capitalista, sino también la separación radical de las diversas formas de ser en el mundo según el discurso de nosotros versus los otros. La modernidad existe por causa de la colonialidad y sus discursos forman parte de la colonialidad del saber y del poder (Escobar, 2003). La modernidad es una narrativa, entre otras narrativas (Fayad, 2016), pero por acción de la colonialidad del poder y del saber se torna en narrativa hegemónica (Mignolo, 2013).

La pretensión de imponer la lógica del mercado capitalista a los pueblos indígenas ha estado acompañada por la penetración del conflicto armado en sus territorios. La guerra en territorio ancestral es ante todo una disputa por la tierra y la pretensión de apropiación de esta. La reacción de las comunidades ancestrales ha sido una lucha espiritual, de resistencia, desde las cosmovisiones, para defender el territorio y la vida que allí se teje. Este es el conflicto central que enfrenta a los pueblos originarios y sus movimientos sociales y al mercado capitalista y sus actores de guerra.

\section{Pueblos indígenas víctimas del conflicto armado}

La irrupción del conflicto armado en territorio ancestral puede rastrearse en los diversos momentos de la historia de Colombia. Los europeos sometieron a las comunidades ancestrales por la fuerza, para imponerles una religión y adoctrinarlas a través del sistema educativo. Durante las guerras de independencia, los pueblos originarios fueron instrumentalizados para participar en estas. La construcción de la república estuvo acompañada de la consolidación de un modelo de nación que impuso una identidad excluyente con los pueblos originarios, que expropió sus territorios y destruyó sus formas de organización y autoridad ancestrales.

La disputa por la tierra y la comprensión del territorio se hizo más palpable a partir de este momento, ya que el modelo monocultural, de matriz individualista, se pretende imponer a toda costa sobre la visión colectiva y comunitaria de los pueblos indígenas, desde la cual establecen su relación con el territorio. Las guerras 
partidistas y el más reciente conflicto armado entre guerrillas y Estado continúan con la instrumentalización de los pueblos, y exacerban el sometimiento de los territorios en los que históricamente las comunidades han construido su vida conforme a sus prácticas tradicionales.

Los grupos armados legales e ilegales han hecho y hacen presencia en los territorios indígenas y ejercen control militar sobre estos. Su presencia obedece a la lógica del conflicto armado, a la necesidad de ganar territorios estratégicos para la confrontación, para la movilidad y para las actividades económicas propias de cada grupo, y además a los intereses económicos de sectores de poder que usan la confrontación militar para el posicionamiento de economías legales e ilegales. La presencia de estos grupos es lesiva para las comunidades, puesto que generan violencia, violación directa a los derechos humanos y el deterioro de sus formas de vida.

Los grupos armados pretenden un dominio sobre los territorios, en algunas ocasiones en asocio, y en otras, en oposición a las élites y los sectores que buscan la explotación de sus recursos. Desde la cosmovisión, la reconciliación pasa necesariamente por el respeto a la vida de la Madre Tierra, del territorio y de la vida de los indígenas en este (Organización Nacional Indígena de Colombia [ONIC], 1998). Los testimonios dan cuenta de cómo las afectaciones del conflicto son amenaza directa a la supervivencia del ser de los pueblos originarios: "Después de que llegó el ejército esto es un caos para nosotros porque [...] se empezó a desplazar por todas las veredas, a todas las veredas” (Entrevista a indígena de la ONIC, 2012).

La presencia de grupos armados en el territorio y su accionar han deteriorado los derechos humanos y las formas particulares de vida y subsistencia de los indígenas. La guerra se convirtió en una amenaza para la supervivencia misma de los pueblos, y esto, claro, desfigura los valores esenciales para el movimiento indígena, como son su identidad, su cultura, su territorio y su autonomía. "El desplazamiento afecta todo y por la pérdida de territorio es perder derecho a nuestra autonomía, derecho a nuestra cultura sí, eso es perder nuestro territorio” (Entrevista a indígena de la ONIC, 2012).

La afectación que aún subsiste de la población indígena ha impactado el valor espiritual de la tierra y del territorio. La armonía de las comunidades con los territorios se torna en "desarraigo" que perjudica la supervivencia de sus tradiciones. Hablar entonces de victimización, en el caso de los pueblos originarios, supone considerar que el daño no es solo material, sino también psicológico, espiritual y moral. Además, la afectación sobre el territorio, teniendo en cuenta su apropiación colectiva, obliga a la consideración de los daños de manera colectiva (Braconnier, 2018). 
La legislación colombiana reconoce como medida de reparación la restitución de tierras. Para el caso específico de la población nativa, la Ley 1448 de 2011 delegó la expedición de una regulación diferencial respecto a la restitución étnica. Los mismos ejercicios de restitución tienden a tornarse en procesos de revictimización. La restitución de tierras se ha visto torpedeada, para el caso de los pueblos originarios, por los tiempos que demanda el proceso y la persistencia del conflicto armado en los territorios ancestrales. Esto se traduce en la presencia tanto de grupos armados que controlan las tierras de la restitución como de los intereses económicos de grandes empresas para la explotación minera (D’Angelo, 2017).

En los territorios de resguardo que han sido y son aún escenario de la confrontación armada, las acciones de guerra se tornan en acciones de alto impacto para las comunidades, puesto que perjudican sus tradicionales formas de vida. Tales acciones logran debilitar el movimiento indígena, porque propician una mayor presencia de fuerzas militares en el territorio. Esto pone en entredicho la autonomía frente a su manejo y control, lo cual crea, además, un clima de miedo por la presencia y el accionar de actores armados que desdibujan las condiciones de armonía propias del relacionamiento de los indígenas con el territorio.

La presencia y la acción de los grupos armados desata el desplazamiento, y la muerte atenta contra la subsistencia de los pueblos ancestrales y contra su "derecho a desarrollarse como pueblos diferenciados [...]. A costa del conflicto armado el capital social y político que han construido los indígenas [...] se viene descomponiendo" (ONIC, 2002, pp. 45-50). Las acciones de guerra realizadas en territorios ancestrales han alterado el equilibrio interno. Han roto con la armonía de los procesos de las comunidades, lo que ha lesionado la identificación con los elementos tradicionales y de orden cultural, y los ha puesto ante una real amenaza de exterminio y etnocidio (onIC, 2002).

\section{El conflicto armado ha lesionado la autonomía territorial}

Son varios los actores que, por diversos intereses, han amenazado y lesionado la autonomía territorial, y como tal han puesto en peligro la existencia misma de las comunidades. Los nasa, del norte del Cauca, ligados a organizaciones históricas del movimiento indígena, hacen una lectura del conflicto y de la manera en que este afecta sus formas tradicionales de vida y sus dinámicas políticas y organizativas, desde una voluntad expresa de afectar lo que se ha ganado en materia de autonomía y territorio. 
Es a partir de esta lectura del conflicto, pero sobre todo de los padecimientos que este les genera, que elaboran una reflexión en torno a la autonomía territorial y llevan a cabo una serie de acciones de movilización, de presión, para defender su postura frente a la guerra, frente al territorio y los actores que lo disputan. "En el norte del Cauca se concentró el conflicto armado... en el territorio, en los sitios sagrados" (Entrevista a líder indígena de la Asociación de Cabildos Indígenas del Norte del Cauca [ACIN], 2012).

Los comuneros entrevistados para este trabajo reconocen la presencia del conflicto en sus territorios desde hace varias décadas. Mencionan que esa presencia ha tenido diversas expresiones y formas de afectación.

El conflicto armado está desde que aparecen las FARC. Han pasado por allí varios grupos como el M-19, el Quintín Lame, el PRT, el Ricardo Franco, que dejaron muchas huellas de dolor y tristeza pero que luego con el acuerdo de paz del 91 permitió cierta calma $[. .$.

Cuando nosotros hacemos acciones de control territorial nos amenazan, son los primeros que nos agreden, son los primeros incluso que nos matan. Vemos una estrategia de los actores de buscar el reclutamiento de comuneras y comuneros. (Entrevista a líder indígena de la ACIN, 2012)

En las regiones se ha asesinado a gobernadores, a miembros de la organización por parte por ejemplo de la izquierda, de las guerrillas. (Entrevista a consejero mayor de la ONIC, 2012)

Los pueblos indígenas habitan territorios que son apetecidos por distintos actores; hay intereses de parte del Estado, de las empresas y de los actores armados. En efecto, estas realidades ya descritas ponen de manifiesto que mientras existan diversos intereses sobre el territorio, su autonomía se va a ver torpedeada. Durante todo este proceso, varios sectores del movimiento indígena sostuvieron el rechazo a la guerra y la necesidad de consolidar la paz como una forma de restablecimiento del equilibrio en los territorios ancestrales.

Decimos esta guerra no es nuestra, la rechazamos y comenzamos a fortalecer todo el tema de la resistencia civil y comunitaria [...]

Nos levantamos en resistencia civil y con la guardia y vamos a quitar trincheras [...] ya no más en los sitios sagrados [...] ya no más retenes que conducen a situaciones de violación de derechos humanos. [...]

[...] Desde este tema de la autonomía tenemos que construir escenarios de paz, hagámoslo en la búsqueda de la convivencia y el desarrollo y el bienestar de todos los colombianos. (Entrevista a líder indígena de ACIN, 2012) 


\section{La victimización en el proyecto de la colonialidad y desde del discurso del desarrollo}

La violencia ejercida en territorio ancestral contra los pueblos originarios se encuentra en sintonía con las formas de imposición de la colonización y su impacto negativo sistemático en las formas de vida de las comunidades. Castillo (2007) refiere la tentativa de las élites blanco-mestizas, que han intentado reducir a los pueblos indígenas e incorporarlos forzosamente al proyecto de nación mestiza en función de configurar la identidad de la nación. El tratamiento que en Colombia, en la lógica de esta configuración monocultural de la nación, han recibido tanto los pueblos indígenas como afrodescendientes es el de razas inferiores.

Escobar (2018) relaciona este tratamiento dado a los pueblos originarios con el proyecto de la modernidad. La modernidad y la colonialidad imponen sobre los territorios ancestrales de los pueblos indígenas la explotación capitalista, arriesgando la subsistencia de la vida misma. Tal afectación de la vida se hace patente en el cambio y el desequilibrio del clima y los ecosistemas, hasta el punto en que Escobar (2011) no duda en calificar a la globalización como un proyecto de muerte. La modernidad, dice Escobar (2003), ha fracasado en ofrecer mundos sustentables. La llamada "episteme moderna” se configura como tal gracias a la colonización y, claro, a partir de toda la devastación, el saqueo y la muerte que ella produjo. Vista en este contexto colonial, la episteme moderna logra imponerse como parte de la gesta colonizadora. La relación ancestral que los pueblos originarios han establecido con la naturaleza ha sido desconocida, y con la colonialidad del saber y el poder es perseguida y en muchas ocasiones derrumbada (Busso, 2009). El daño a la naturaleza es efecto de la relación mercantil que se establece con ella. Esta relación impone una postura antropocéntrica de la episteme moderna en la que el ser humano es visto como individuo, dominador y centro de la vida.

La modernidad y su discurso del desarrollo riñen con las cosmovisiones de las comunidades y, por ende, con sus maneras de relacionarse con la vida en el territorio. Los pueblos originarios de América Latina son poseedores y constructores de una ontología relacional. Esto significa que su ser está ligado esencialmente a las demás formas de vida, en armonía con la tierra, subordinando los objetivos económicos a criterios ecológicos. El universo pluriverso, según Escobar (2018), que es la vida como flujo, no es un espacio inerte para ser ocupado, sino un todo vivo con el que se habita. En tal sentido, estos pueblos ponen en cuestión la categoría impuesta desde la modernidad occidental del subdesarrollo (Escobar, 2011). 
El territorio para los llamados por Escobar (2018) pueblos-territorio es el espacio vital que asegura la vida desde la cultura. Escobar se refiere al territorio como el libro histórico que mantiene vivas las tradiciones de sus habitantes. Esta concepción le confiere sentido ontológico a la liberación de la Madre Tierra. Liberarla es más que simplemente recuperarla; es relacionarse con ella de una manera distinta a como lo ha hecho el capitalismo en la episteme moderna. No es solo liberar a la Madre Tierra. Es también liberar a la vida que habita en ella, liberar el pensamiento, la identidad, la conciencia, y construir en la tierra liberada territorio para la vida digna de todo y todos. Cada espacio liberado se suma al restablecimiento de este equilibrio con la vida. "No es el hombre quien liberará la vida, sino estos pueblos quienes al liberar la Tierra liberarán la vida” (Escobar, 2018, p. 94).

El territorio ha recibido violencias que se derivan de los intereses económicos que diversos actores persiguen en él. El conflicto armado en el territorio sigue la lógica del capitalismo y el discurso del desarrollo. Los actores del conflicto armado intervienen en los territorios en contra de las formas de relacionamiento de los pueblos indígenas con estos. Por eso los pueblos originarios hablan de liberación de la Madre Tierra y, desde este enunciado, postulan el retorno a relaciones armónicas con el territorio. La paz, desde la comprensión de las comunidades indígenas, pasa por la consideración, desde las cosmovisiones, de una relación de armonía en el territorio y con el territorio.

\section{La propuesta de paz desde los pueblos indígenas}

Los pueblos originarios tienen una relación con el territorio que interpela toda su vida. La violencia que se ejerce sobre este, su explotación y la ocupación por actores de guerra configuran un escenario de victimización que trasciende la mirada individual y se constituye en afectación a la integralidad de la vida de estas comunidades.

Luego de esta sucinta mirada a algunos de los procesos de victimización hacia los pueblos indígenas, y considerando que la imposición del proyecto modernizador sobre el territorio se constituye en un elemento más de victimización hacia el colectivo, cabe introducir algunos apuntes en relación con la perspectiva de reconciliación y paz que plantean algunas de las comunidades ancestrales más afectadas por el conflicto armado en Colombia. La comprensión de la paz debe atender a la mirada de quienes han sido víctimas. En el caso de los pueblos, además de ser víctimas individuales, su victimización ha sido colectiva. Ellos han visto afectada su identidad como pueblos, sus dinámicas autonómicas y su existencia misma por cuenta del 
conflicto. Por ello le plantean no solo una visión, sino más bien muchos interrogantes a los temas de paz y a la manera como las discusiones a este respecto se dan en el país, en el marco de los acuerdos de paz.

La afectación sobre pueblos originarios se ha dado por procesos territoriales y socioeconómicos que ponen en riesgo la cultura y la vida misma. Los pueblos indígenas son víctimas en tanto colectivo, en la medida en que el conflicto armado afecta su territorio y su cultura. La dimensión colectiva se evidencia también en su comprensión de la paz; para los indígenas, la paz es una "reconciliación ciudadana" entre todos los actores de la sociedad para evitar la continuidad de la violencia (Grupo Copal, 2014).

Juvenal Arrieta, en relación con las negociaciones de paz, indica:

Saludamos que estas iniciativas marquen una ruta hacia la desmovilización de las FARC, y por supuesto una esperanza hacia la paz, pero creemos que las reglas del juego que nos deben satisfacer son las que se construyan con todos nosotros, no solo con indígenas, sino con los sectores de la sociedad, porque la paz se hace es en la sociedad, no entre armados, ellos armarán los acuerdos de desarme, de no utilizar más el fusil, pero la reconciliación, la consciencia de paz, la capacidad de perdonar está en los corazones de los ciudadanos. (citado por el Grupo Copal, 2014, p. 13)

Los pueblos originarios, desde los inicios de la vida de las organizaciones del movimiento, vienen hablando de la paz como:

Una paz que la hemos venido plateando desde hace 45 años, cuando creamos el Consejo Regional Indígena del Cauca (CRIC), una paz que la hemos venido construyendo a pulso y en medio de la confrontación armada [...] Una paz que es integral, una paz que es ancestral, una paz que es milenaria y una paz que no está fijada solamente para el mundo indígena sino para toda la humanidad, porque solo así podríamos hablar de una paz verdadera y duradera en Colombia. (Entrevista a líder indígena de $\mathrm{ACIN}, 2016)$

Con base en esta comprensión, los dirigentes del movimiento ven con preocupación los desarrollos de los procesos de negociación entre las guerrillas y el Gobierno, y la manera en que se está adelantando la implementación de lo acordado. Estas preocupaciones se derivan necesariamente de la experiencia misma frente a la guerra en Colombia. Esto por lo que ya se ha planteado en relación con el impacto en el corazón mismo de la lucha indígena, del territorio y de su proyecto de vida, del conflicto. 
Los pueblos originarios, pese a haber vivido los rigores de la guerra y de ser y continuar siendo victimizados por el conflicto, han saludado los acuerdos y los procesos de negociación. Hay que reconocer que como un gesto de pazy de reconciliación, en diversas ocasiones las comunidades han ofrecido sus territorios y su mediación para que en el seno mismo de los resguardos se adelanten diálogos con los actores armados, con un enfoque territorial. La reconciliación pasa necesariamente por la consideración de los asuntos de fondo que acompañan el conflicto. Las comunidades ancestrales hablan de una paz integral que pase por la garantía del derecho y por el reconocimiento de la diversidad.

Tiene que ser una paz donde se respete el pensamiento del otro, no una paz que se imponga, tiene que ser una paz que sea muy coherente con la diversidad de lo que es el pueblo colombiano. Tiene que ser una paz para todos, no puede ser una paz para unos solos, como ha venido ocurriendo. $Y$ tiene que ser una paz que donde lo que está escrito se cumpla, porque no podemos seguir con gobiernos que se comprometen, que prometen, que firman lo que la gente diga pero que no se cumple, mejor dicho, una paz que nos permita vivir contentos, tranquilos y eso solo se da si se reconoce al otro. (Entrevista a líder indígena de ACIN, 2016)

En su visión de la paz, como lo plantea Zibechi (2015), despliegan una comprensión de una temporalidad en la que se apela a la paciencia, a la construcción detallada y al pasado, al descubrimiento de lo oculto. Este autor habla de los movimientos sociales como redes en movimiento. Tanto los movimientos como el indígena, dice, son estructuras abiertas, distintas de las tradicionales formas de hacer política. Su origen, en América Latina, son las márgenes y el conflicto que desde la marginación libran los excluidos. En su forma de organización y acción se reconoce que se sintonizan con las lógicas de su cotidianidad. Tienen más que una presencia en la esfera central de las disputas por el poder, un fuerte arraigo y presencia territorial desde la que ofrecen alternativas a la política tradicional y desde el carácter comunitario y no capitalista de la cotidianidad en la que actúan.

Las principales luchas de estos actores, así organizados, son por el reconocimiento. En el caso de los movimientos indígenas, su lucha es, además que por el reconocimiento de su carácter diferencial, por la restauración de valores que se han perdido. En este sentido, apelan no a una idea de progreso o desarrollo, sino a la comprensión de que lo nuevo que se quiere construir ya está en lo viejo, en el equilibrio perdido, en la armonía olvidada, en las realidades que la hegemonía y la colonialidad del poder y el saber han ocultado. Escobar (2011) insiste en la necesidad de 
superación de la dicotomía que impone el discurso del desarrollo entre pueblos desarrollados y pueblos subdesarrollados. En esta lógica, las comunidades ancestrales ofrecen al país una nueva ética que pone los objetivos ecológicos por encima de los económicos.

La paz la tenemos que construir todos, no sabemos cuánto nos demoremos en eso, pero la construcción es entre todos [...] otra paz es la que pensamos los indígenas: estar tranquilos, que no violenten nuestros territorios, que tengamos acceso pleno al derecho a la tierra, que nos gocemos los derechos que están establecidos en la norma, que nos entendamos y que nos juntemos todos para ver si algún día cambia esta situación [...]. La paz que nos pensamos nosotros tiene que ser una paz con todas las garantías que necesitamos para que podamos vivir en paz. (Entrevista a líder indígena de $\mathrm{ACIN}, 2016)$

La reconciliación que el país demanda y que va a permitir que la paz sea duradera supone atender al reconocimiento del carácter diferencial de los habitantes del país y, por su puesto, de las víctimas de la guerra y del conflicto. Walsh (2009) presenta el tema del reconocimiento de la diferencia como la lucha de los grupos subalternizados, siguiendo la caracterización construida desde el proyecto modernidad-colonialidad. Este proyecto viene planteando la existencia de otras epistemes distintas a la moderna, y como tal de la posibilidad de existencia más allá de la relación trazada por las prácticas discursivas de la modernidad. La praxis política de los subalternizados ha de ser considerada, según esta perspectiva de análisis, como una fuerza epistémica que impulse los proyectos locales de las comunidades (Escobar, 2003). Las luchas indígenas por la defensa de la diferencia, de la naturaleza, de otras economías, muestran el resultado de la resistencia milenaria y de las luchas de movimientos sociales ligados a la tierra, al territorioy a lasidentidades colectivas de orden cultural.

La exclusión ha sido la forma a través de la cual se han considerado desde Occidente las prácticas ancestrales. Sus subjetividades y racionalidades no han tenido cabida en la historia occidental. Las prácticas discursivas desde la episteme moderna han significado exclusión para los pueblos originarios, mientras las prácticas discursivas de estos pueblos se configuran según los enunciados de la liberación (Escobar, 2018).

¿Cómo entender la liberación de la Madre Tierra desde la episteme moderna? Para Escobar (2018), este es un enunciado lejos de la modernidad. La sola 
apreciación de la tierra como madre es ya una consideración epistemológica y ontológica. No es solo un discurso, es una realidad. Es la Madre Tierra y sus entidades espirituales las que impulsan la vida y las prácticas en el mundo indígena. Escobar habla de nuevas prácticas discursivas a partir de este enunciado de liberación de la Madre Tierra. Para él, tales prácticas no son nuevas, pues habitan en el mundo indígena desde hace muchos más años que los que pueda tener la episteme occidental imponiéndose en América Latina. Las nuevas prácticas discursivas vienen siendo reconocidas recientemente por las prácticas políticas de los pueblos originarios. La proclama de liberación de la Madre Tierra es una práctica entre los pueblos, pero es un enunciado para el mundo entero con base en las movilizaciones ligadas a la tierra y el territorio.

Para el caso de América Latina, estas prácticas discursivas vienen calando en las construcciones políticas que las luchas indígenas han llevado hasta los centros de discusión política, hacia la sociedad mayoritaria y hacia las instancias de poder. Lo que la práctica discursiva de los pueblos originarios propone es incorporar en la vida global el carácter relacional de las ontologías indígenas. Los pueblos ancestrales viven sobre la base de relaciones de respeto y equilibrio con la naturaleza. Los seres de la vida habitan el planeta y este no es un recurso para enriquecerse a partir de su explotación, sino parte de la vida misma de los seres. Esta relación con la tierra y la vida supone construir nuevas formas de conocer, pensar y ser.

Desde las luchas de los pueblos se pugna por el avance de cambios con los cuales se pretende afectar las estructuras del poder. A partir de la politización de la diferencia los pueblos originarios configuran una reflexión en torno a una paz estable, duradera, incluyente, como un camino que se construye con base en la reconciliación. Esta reconciliación, para ellos, tiene unas condiciones ligadas al contenido mismo de sus luchas desde la politización de la diferencia.

Si aquí no hay un reconocimiento pleno de los grupos étnicos, va a ser muy difícil hablar de paz. Si aquí siguen discriminando al negro, al campesino, al indio o al pobre, ¿cómo vamos a construir la paz? Si aquí se habla de que la salud y la educación son derechos que la gente tiene, pero que no se ejecutan, ¿cómo vamos hablar de una paz? Mejor dicho, aquí hay mucho tema para hablar de paz si estamos pensando en una paz verdadera; eso es lo que los indios venimos planteando en asuntos de paz, otra cosa es que se termine el conflicto armado y ojalá sea pronto que se firme eso rápido para ver cómo es que nosotros vamos a caminar a la hora de la construcción de la paz. (Entrevista a líder indígena de ACIN, 2016) 


\section{Conclusiones}

El conflicto armado ha tenido un particular impacto en los pueblos originarios y en las luchas del movimiento indígena en Colombia. Los grupos paramilitares, las llamadas "bandas criminales", los agentes del Estado y las guerrillas, las desmovilizadas y las que actúan como grupos residuales después del acuerdo para la finalización del conflicto con las FARC, han resultado particularmente lesivos para la vida de los pueblos indígenas y para las luchas del movimiento social que los articula. Además del accionar militar que ha golpeado a las comunidades, en Colombia ha habido una tendencia por parte de los actores armados, de actores de poder y económicos, a establecer un control sobre el territorio, sus recursos y sus dinámicas económicas.

La victimización de los pueblos originarios y del movimiento social que los articula ha generado importantes tropiezos y amenazas para la existencia de estos pueblos, sus dinámicas y sus formas de vida. Entonces, como una manera de resistir, de mantener su proyecto, de defender uno de sus pilares, que es la autonomía, los indígenas se aventuran a hablar de la paz como escenario de reconciliación en el que, desde el reconocimiento de la diversidad, se lleven a discusión sus problemáticas en relación con el territorio, con los actores que se lo han disputado. Se busca el escenario donde se avance hacia la conquista del reconocimiento de la autonomía como valor indispensable para los indígenas, pero también para otros sectores sociales en Colombia.

Y como ya se ha venido evidenciando, la propuesta del movimiento indígena en relación con la reconciliación va más allá de los discursos y los lugares comunes en torno a la paz, y se materializa en acciones tendientes a hacer avanzar el reconocimiento de la diversidad y el respeto del derecho a ejercer, desde ella, las dinámicas propias de los pueblos ligadas a su ser y su permanencia en el tiempo, al igual que su inserción en la dinámica de la nación. En este espíritu, los pueblos indígenas despliegan acciones de reivindicación que hacen avanzar la paz. En el caso particular de las acciones tendientes a la desmilitarización y la limpieza de sus territorios, estas se inscriben como discursos simbólicos que obligan a quienes están en la guerra y a quienes le hacen daño a las comunidades, a pensar esa realidad de la guerra y la paz con un lenguaje distinto al de las armas, con un enunciado distinto al del desarrollo a partir del interés egoísta. Esta es su práctica de reconciliación.

En esta lógica, los indígenas hablan de la limpieza del territorio y de su armonización, y en ello se ve evidenciada su visión de la reconciliación, que pasa por la restitución del equilibrio. En este tipo de iniciativas, los indígenas quieren avanzar hacia la presentación a la sociedad colombiana de una manera de proceder para defender 
sus valores. Y para ello, reclaman el concurso y la solidaridad de la sociedad colombiana. Entonces, si la sociedad colombiana lee estas acciones como iniciativas en el marco de la construcción de verdadera democracia y restitución del equilibrio, serán acciones contundentes que harán avanzar la paz en el país.

La manera en que el conflicto armado y el accionar, en ocasiones violento, de unos actores ha afectado y afecta la vida y la tranquilidad de las comunidades evidencia que la autonomía y el reconocimiento de la diversidad pasan por el ejercicio de los derechos. En el caso de los indígenas, esto se liga a la tranquilidad para el desarrollo de su proyecto de vida en el territorio, y en el restablecimiento de dichas condiciones está la base de la reconciliación. La injerencia del actor armado desde su proyecto político, en las dinámicas regionales y nacionales del movimiento indígena, pone en entredicho el proyecto político de este y se convierte en factor de desequilibrio y conflictividad. El conflicto por la autonomía territorial se convierte en un elemento de oposición entre el modelo de sociedad que proponen los indígenas sobre la base de su experiencia y de los valores que en la cultura han adquirido y los modelos que proponen el Ejército, el Gobierno, las élites políticas, los sectores económicos, los paramilitares, los narcotraficantes y las guerrillas.

La autonomía territorial como materialización del reconocimiento de la diversidad de los derechos es un valor superior del movimiento indígena, un pilar de su aporte a la democracia en la nación y un elemento en disputa en el conflicto. El balance presentado da cuenta del avance en la configuración de un discurso y unas acciones de defensa de la autonomía, desde el posicionamiento de formas y valores propios de la cosmovisión indígena. Hay, sin embargo, una lesión permanente por parte de los actores del conflicto que en el marco de la consolidación de la paz exige la reconciliación. La propuesta de reconciliación como camino hacia la paz de los indígenas se enmarca en la defensa de sus derechos como pueblos diferentes, en su derecho como colombianos y en el avance hacia una paz que respete su diferencia, que restablezca la armonía y el equilibrio en el territorio y que considere su aporte a la democracia de todos los colombianos.

\section{Sobre los autores}

Carlos Alberto Osorio Calvo. Filósofo de la Universidad Nacional de Colombia. Magíster en Sociología de la Universidad del Valle. Estudiante del Doctorado en Educación en la Universidad del Valle, Colombia. Actualmente es docente de la Universidad del Valle y de la Escuela Normal Superior Farallones de Cali. Es investigador en el campo de la sociología y la pedagogía sobre movimientos sociales, movimiento indígena, educación propia de los pueblos indígenas, educación intercultural. Ha publicado recientemente en las revistas Praxis Filosófica, Revista Kavilando y El Ágora. 
Melania Satizabal Reyes. Terapeuta ocupacional. Especialista en Desarrollo Comunitario. Magíster en Sociología de la Universidad del Valle. Docente de la Escuela de Rehabilitación Humana de la Universidad del Valle. Sus áreas de interés son: desarrollo comunitario, sociología del trabajo, discapacidad, terapia ocupacional comunitaria. Ha publicado recientemente en las revistas Cadernos Brasileiros de Terapia Ocupacional, Revista de Salud Pública y Revista Argentina de Terapia Ocupacional.

\section{Referencias}

Braconnier, L. (2018). Los derechos propios de los pueblos étnicos en el Acuerdo de Paz de agosto de 2016. Derecho del Estado, (40), 113-126. Dor: https://doi.org/10.18601/01229893. $\mathrm{n} 40.05$

Busso, H. (2009). Crítica al eurocentrismo como obstáculo epistemológico. Perspectivas de la filosofía latinoamericana. Solar, 5(5), 59-80.

D’Angelo A. (2017). Restituir las tierras en el marco del posconflicto colombiano: una mirada al caso indígena Wiwa de la Sierra Nevada de Santa Marta. Periféria, 22(2), 112-135.

Escobar, A. (2003). Mundos y conocimientos de otro modo. El programa de investigación de modernidad/colonialidad latinoamericano. Tabula Rasa, (1), 51-86.

Escobar, A. (2011). Una minga para el postdesarrollo. Signo y Pensamiento, 30(58), 306-312.

Escobar, A. (2018). La forma tierra de la vida. El pensamiento nasa y los límites de episteme de la modernidad. Otro posible es posible: caminando hacia las transiciones desde Abya Yala/ Afro/Latino-América. Bogotá: Ediciones Desde Abajo.

Fayad, J. (2016). ¿Es posible salir de la exclusión, racismo y racialidad? La ancestralidad y la espacialidad, fundamentos en la forma escuela en pueblos indígenas. Buenos Aires: Clacso.

Grupo Copal (2014). La participación de los pueblos étnicos en la negociación del fin del conflicto armado colombiano. Revista de Derecho Público, (33), 1-23.

Meza, G. (2016). Justicia nosótrica para la paz: desde la memoria hacia la utopía. Panorama, $10(18), 40-49$.

Mignolo, W. (2013). Geopolítica de la sensibilidad y del conocimiento. Sobre (de)colonialidad, pensamiento fronterizo y desobediencia epistémica. Revista de Filosofía, 74(2), 7-23.

Organización Nacional Indígena de Colombia. (1998). Memorias del Quinto Congreso Indígena Nacional. Bogotá: ONIC.

Organización Nacional Indígena de Colombia. (2002). Vida y dignidad para los indígenasy para los colombianos también. Memorias del Congreso de los Pueblos Indígenas de Colombia 2001. Bogotá: Turdakke.

Rodríguez, A. I. (2018). Las voces étnicas en el Acuerdo de Paz de Colombia: una resistencia ontológica. Relaciones Internacionales, (39), 165-183. 
El movimiento indígena como víctima del conflicto armado en Colombia...

Touraine, A. (1998). Igualdady diversidad. Las nuevas tareas de la democracia. México: Fondo de Cultura Económica.

Touraine, A. (1999). ¿Cómo salir del liberalismo? Barcelona: Paidós.

Touraine, A. (2010). ¿Podremos vivir juntos? Iguales y diferentes. México: Fondo de Cultura Económica.

Villa, J. D. (2016). Perdón y reconciliación: una perspectiva psicosocial desde la no violencia. Polis, 15(43), 131-157.

Walsh, C. E. (2009). Interculturalidad, Estado, sociedad: luchas (de)coloniales de nuestra época. Quito: Universidad Andina Simón Bolívar.

Zibechi, R. (2015). La construcción de otro mundo en América Latina. Descolonizar el pensamiento crítico y las prácticas emancipatorias. Bogotá: Ediciones Desde Abajo. 